\title{
Useful Creativity: Vernacular Reviewing on the Video-Sharing Platform Vimeo
}

\author{
By Maarit Jaakkola
}

\begin{abstract}
This article intends to cast light on the phenomenon of non-institutionalised or vernacular reviewing by studying the review videos published on the video-sharing platform Vimeo. The data were automatically retrieved by searching for videos provided with the hashtag \#review. The majority of these review videos $(\mathrm{N}=1,273)$ were related to the technical equipment of filming and produced by filmmakers and enthusiastic amateurs interested in camera equipment and digital filming quality. The analysis describes the forms of reviewing in these videos and attempts to place them in the conceptual framework of reviewing, which, as is suggested in the article, reaches beyond the professional reviews commissioned by legacy media. Central questions are the delivery of an opinion or judgement, the imagined audience and the establishment of authority. Vimeo reviewers are characterised as both "professional vernacular" and "amateur vernacular" reviewers, reflecting a two-direction approach to reviewing, the one from cultural production (produsage) and the other from cultural consumption (presumption). The findings call for more conceptual elaboration of vernacularity in cultural critique.
\end{abstract}

Keywords: Online reviewing, user-generated content, cultural engagement, cultural production, cultural intermediation, cultural produsage.

Jaakkola, Maarit: "Useful Creativity: Vernacular Reviewing on the Video-Sharing Platform Vimeo", Culture Unbound, Volume 12, Issue 2, 2020: 373-392. Published by Linköping University Electronic Press: http://www.cultureunbound.ep.liu.se 


\section{Introduction}

In the era of mass media, reviewing new cultural products on the market was for a long time a task for professional journalists, reviewers and critics only. Due to the technological possibilities of the internet, producers of goods and services have learned to endorse amateur and consumer product reviews, and the platform economy has produced forums for ordinary people to start evaluating those products out of their own initiative. Because of these changes, the definitions of reviewing should be reconsidered and examined in digital platforms as an online-native phenomenon.

This article takes a look at one particular form of reviewing on one platform: review videos published on the popular global video-sharing service Vimeo. The analysis, based on videos provided with the hashtag \#review, intends to find out how reviewing is manifest in the Vimeo community and how the general characteristics of reviewing applies to this specific context. Examining the range of user-generated reviews can increase our understanding of how people form evaluative relationships to cultural products and, more generally, how cultural relationships to today's goods and services are constructed on social media. Vimeo's review videos present an online-native and bottom-up form of reviewing new cultural products, casting more light on the cultural engagement of the audiences and consumers.

The focus of this analysis is on mapping and describing the applications of the genre of review in relation to different topics on Vimeo, a video platform that is less driven by entertainment goals than the more mainstream and popular video platform YouTube. The analysis is part of an endeavour to understand the creation of reviews by ordinary people in non-institutionalised settingsso-called vernacular reviewing. As the review videos provide us with a niche that is comparable across platforms, the study may also deliver information on how Vimeo potentially differs from YouTube, which seems to have developed some very distinct ways of "grammars" penetrating genres, inclusive reviews, such as unboxing, let's plays and tutorials (see Jaakkola 2018).

I will first place the Vimeo review videos in the context of the genre of reviewing. Thereafter, I will offer a brief look at Vimeo as a video publishing and sharing platform in the social media ecology. The empirical analysis focuses, first, on the identification of different types of review videos, examined through the cultural objects chosen for review (what is reviewed). Second, the analysis moves on to a more qualitative approach based on the identification of usefulness being a central dimension of the genre. Instead of focusing on individual producers, the analysis seeks to find common traits in the video reviews by describing common characteristics of the type of reviewing that Vimeo review videos represent. At the end of the article, I will discuss the place and the significance of usefulness 
in the user-generated reviews as they appear on Vimeo. My hope is that the analysis on Vimeo reviews will add to our knowledge of vernacular reviewing as a platform-specific online creativity, related to a digital-native genre.

\section{Institutional and Vernacular Reviewing}

The genre of review refers to a form of presentation in which an author creates, motivates and delivers an informed opinion about a cultural object to the public (Blank 2007). Reviews are "public summaries and evaluations that assist readers to be more knowledgeable in their choice, understanding, or appreciation of products or performances", answering two questions: "what is it? Is it any good?" (Blank 2007: 7).

"Criticism" and "reviewing" have typically been implied to mean assessments of quality, with "reviewing" subordinated to the more serious and legitimate "criticism" (Carroll 2009, Hohendahl 1982). Criticism is "studied evaluation" (Titchener 1998: 3) or "evaluation grounded in reasons" (Carroll 2009) that is used to describe an expert's evaluation of an event, while a review is "a report with opinion", characterised by a journalistic "who-did-what-when approach" and typically written for a wider audience by a generalist who qualifies as "an entertainment writer with a host of newspaper-based obligations" (Titchener 1998: 3). Whereas criticism is expected to go deeper into the contexts of production, the (institutionalised form of) reviewing is supposed to deliver a motivated opinion in a convincing way.

The traditional institution of reviewing (see, e.g., Hohendahl, 1982) has been challenged by modifications in technology and culture (see, e.g., Corner, 2013; Gillespie, 2012). So far, it has become common to distinguish between professional and amateur reviews (Verboord 2010, 2011, 2012, 2014; Kammer 2015, Steiner 2010). The relationship between the institutionalised or classical criticism and the online-native genre of (amateur) review has been examined in terms of migration from old media to new platforms (Domsch 2009, Orlik 2016, Rixon 2017, Gillespie 2012), a manifestation of diversification and democratization of opinion (McWhirther 2016, Frey \& Sayad 2015), and professionalisation of the amateur activity of reviewing (Beaudouin \& Pasquier 2017, McAuley \& Leskovec 2013, Beuscart \& Mellet 2016). The starting point for an increasing research interest is that, since the advent of the technological possibilities provided by social media, an increasing number of self-titled reviewers, in contrast to reviewing professionals who are commissioned and paid by media organisations and users contributing to platforms with pre-established amateur roles and genres, are producing reviews (Rixon 2017, Gillespie 2012). These reviews are more and more often published on so-called multi-purpose platforms where no generic expectations and restrictions 
are available, in the way that the many platforms such as Internet Movie Database (IMDb) or Rotten Tomatoes are designed to publish "customer" or "amateur reviews"; instead, the users producing evaluations on cultural products are free to define the content of the genre and move from one storytelling mode to another to fulfil the reviewing function. The works published are not only limited to the written text, and not even to a single platform, content being spread across different platforms to reach different audiences.

In other words, evaluations of cultural products by ordinary people are non-institutional cultural forms and practices, as they are not coherently supported by any organisations that would centrally define the objectives and means of reviewing (Howard 2010). Vernacular uses of discourses emerge "from discussions between self-identified smaller communities" within larger communities and have been conceptualised as an expression of alterity to the institutional power (Howard 2010, Conti 2013). Being in a dialectical relationship with the institutionalised forms of discourse, vernacular discourses emerge through the appropriation of dominant discourses in ways that are better suited to the vernacular community (Conti 2013, Howard 2008). Theorists of vernacularity have thus viewed the institutional and the vernacular as fundamentally inseparable, with the vernacular establishing its meaning by asserting itself against the institutional (Howard 2008, 2010).

At a more general and less genre-specific level, the participation or online practices by ordinary users have been captured, above all two concepts that are of relevance here: "vernacular creativity" (Burgess 2006) and "platform vernacular" (Gibbs et al. 2015). Burgess (2006: 206) defines vernacular creativity as "the process by which available cultural resources-are recombined in novel ways, so that they are both recognizable because of their familiar elements, and create affective impact through the innovative process of this recombination." Platform vernacular adds the production context to this activity, referring to "shared (but not static) conventions and grammars of communication, which emerge from the ongoing interactions between platforms and users" (Gibbs et al. 2015: 257).

Vernacular reviewers are thus employing strategies of institutionalised reviewing, but they may give the activity altered meanings. As criticism and reviewing can be seen as ends of a sliding scale, where criticism represents in-depth analysis with more requirements for argumentation and reflexivity and reviewing denotes a more non-reflective, spontaneous reaction to a cultural object, the categories of "professional" and "amateur" reviewing can be regarded as parts of a continuum. The same applies to the degree of institutionalisation, i.e., between institutionalised forms of professional and amateur reviewing and their non-institutionalised counterparts. While the institutionalised forms of reviewing are typically attached to high culture aesthetics and the aesthetics of 
everyday life, vernacular reviews more typically deal with popular culture and ordinary consumption (Gronow \& Warde 2011), setting the focus beyond the artistic realm. Within this broad spectrum, they are likely to show a wide scale of rationalisation of practice that position the producers very differently and render their own standards of quality.

\section{Vimeo as a Video-sharing Platform}

Vimeo, just like the more popular video platform YouTube, is a video-sharing website in which users can upload, share and watch videos. Vimeo was founded three months before YouTube, in October 2004, by two American entrepreneurs, Jake Lodwick and Zach Klein. Vimeo became known for its early technological advancements, as it established a video-on-demand service (VOD) and supported HD earlier than YouTube.

Vimeo is often seen as an alternative or opposite to YouTube, which has, as one of the most frequently-used social media platforms in the world, received more of a mass audience and popular character. As a smaller and more limited community, it is regarded as more "indie", more "mature" and "tasteful", more "supportive", and more "professional" or "academic" (see, e.g., Quora 2018). Unlike YouTube, Vimeo does not run advertisements, but is based on a premium model that allows users to upgrade their free accounts to Plus or Pro level. In its corporate narrative, Vimeo presents itself as "a supportive community covering a wide range of interests" and "a community of real, amazing humans" (Vimeo 2018c).

An audiovisual media environment has been less discussed in the context of reviewing, which, at least in regard to amateur forms, has had a focus more on blogs, in which the written text is central, and podcasts, which are based on oral communication. The review video thus features a distinct form of user-generated reviewing, placing visual and oral means and faces (personalities) in more an important role than in other reviewing activities. Reviewing has, however, institutionalised roots even in the broadcast media. Most television reviews have, indeed, been focused on films, like the long-running television review programmes presented by Robert Ebert and Gene Siskel (At the Movies in the U.S.), Barry Norman and Jonathan Ross (Film on the BBC in Britain), or Margaret Pomeranz and David Stratton (The Movie Show on the ABC in Australia).

Vimeo allows videos in all genres, with the only condition that they should be original and indicate creative expression. In video cultures, different forms of metacommentaries have become increasingly common, as shown in the video genres of tutorials (e.g., cosmetics), walk-throughs (e.g., gaming), experiments (as used in many pranks or life hacks), and many others (Jaakkola 2018). Ordinary 
users may show how they play a game, put on makeup, cook, eat, or perhaps play with toys, and share these experiences with other users. Even if many of these acts may only have an entertaining function, in attachment to these filmed activities the users have the possibility to create critical distance from the cultural products and act as "everyday amateur experts" by commenting, interpreting, evaluating, contextualising and improving the activities related to the cultural products (Kristensen \& From 2017).

As with any other platform, the video platform creates affordances that both enable and restrict certain functions and activities. The possibility of ad-free displays on Vimeo may play a role for reviewers and add to its attractivity. Since the mediating organisation that has traditionally guaranteed the detachment of intermediaries from production is omitted in the vernacular forms of reviewing (see, e.g., Shirky 2008), vernacular reviewers act closer to the industries producing the products to be reviewed. Explicit commercial content is more seldom seen on Vimeo, as promotional videos (e.g. product demos) and videos focused on short-term sales (e.g., real estate walk-throughs) are advised to be kept private on Vimeo (Vimeo 2018c). However, commercial content is allowed: "As long as you make it clear in the description that you are sharing the video as an example of your creative work and not as an actual advertisement, you can upload videos with commercial content even if you are not a PRO user. To qualify for this exception, you must be an independent artist or a production company or a non-profit organization" (Vimeo 2018b).

Vimeo may also attract producers who do not strive for the widest possible audiences and highest grade of visibility with a strategic plan of becoming "influencers" or otherwise turning their activities economically beneficial, but in the first place just want a platform on which to share their work. This way, the platform also creates a horizon of expectations regarding the form and style of the content. On Vimeo, films and filmmaking form a normative centre which the content is typically mirrored against. Indeed, the name Vimeo is an anagram of the word "movie" - as well as a combination of "video" and "me" - and thus the focus is expected to be on films. However, as can also be seen in the sample, many users do not necessarily make an exclusive choice between Vimeo and YouTube but have accounts on both, perhaps in the hope of reaching different audiences or temporarily testing out which platform functions better, or to gain practical knowledge of them both as a publisher.

Vimeo has adopted the term "Vimeans", a counterpart to "Tubers" on YouTube, to refer to the members of the community, thus implying a sense of affinity and exclusivity. Vimeo calls the video publishers "creators", in the same fashion than YouTube has established the term "content creators" to denote the users producing, publishing and sharing videos. These users may be individual persons, 
collectives or organisations of different kinds. In the following, I will call the users "producers", following the terminology used to describe cultural production (see, e.g., Alexander, 2010). I will also use "cultural product" to refer to the cultural object exposed for review. The "product" can be any kind of identifiable object that is set under review, from a concrete item to a service, and from an event to a person, as can be seen below.

\section{Data and Method}

The data were collected on the website Vimeo.com among published and thus publicly available video material. Based on the possibilities and restrictions provided by Vimeo's API, a script for Vimeo was created. The script, released as an open software on GitHub ${ }^{1}$, automatically retrieved videos provided with the hashtag \#review, limited to videos with a minimum of 10 likes. The retrieved information included the username, the user URL, the number of likes, and the number of followers of the username, which are all public information. The data retrieval occurred in July 2017 and the output data is dated July 13, 2017.

The data collection retrieved a total of 1,661 videos. Besides content that could be regarded as review videos, the sample included videos that did not show reviewing character even if tagged as \# review: original films, film trailers to be reviewed later or elsewhere, PR material and other miscellaneous content that did not relate to the review genre. The sample was manually coded by separating review videos (1) from non-review videos (0). A review video was thus expected to show original content that comments or otherwise builds a relationship to a cultural object or objects. The coding resulted in 1,273 videos categorised as "review videos", which formed the sample for the further analysis. The qualitative analysis of videos was based on identification of the main types of review videos (what kind of cultural products were reviewed in the videos?) and their characteristic common characteristics, which are condensed around the concept of "usefulness". The sample being limited to videos with some or a high degree of interaction between the producers and viewers, seen in the number of likes $(10-3,879)$, the sample may overlook some reviews that would be relevant for theorising about reviewing but have not built up any dialogical audience relationship (i.e., have nine or fewer likes). This might be the case with videos that have only been published on Vimeo but in fact consumed somewhere else by embedding the videos on external websites. However, due to the API restrictions causing it not to be possible to automatically retrieve the number of views per video, the sampling method could not be based on actual views. The number of likes and followers of individual producers may, nevertheless, function as some sort of quality control; videos with no interaction often turned out to be material of varied quality and 
with no clear connection to reviewing. Furthermore, it has been found that the more popularity the user reviewers gain, the more "objective" their reviews tend to become (Goes et al. 2014). Besides, since reviewing is typically a continuous activity by someone who wants to profile as a reviewer, it can be assumed that a serious and continuous activity sooner or later brings forward at least some online interaction.

As said, the material analysed in this sample is public: it has been published online and shared to an unlimited audience on Vimeo. While bearing in mind that the mere availability of data does not directly mean that it can be used for research purposes (see e.g. Zimmer 2010), in this case, the producers under study explicitly position themselves as publishers of public content, making explicit claims for authorship, which means that they can be conceived of as publishers and their channels can be juxtaposed to public media. This condition differs from social networking sites where people appear in different and more private roles such as commentators in a virtual debate, possibly not even being aware of the public character of their appearance. Nevertheless, to protect the privacy of individual reviewers, the producers' activities are described at a general level as much as possible instead of focusing on individuals who can be identified.

\section{Types of Review Videos}

The identifiable product groups reviewed in Vimeo reviews are presented in Table 1. It can be seen that the overwhelming majority of the review videos were focused on technical equipment $(\mathrm{N}=1,004)$, which made up 79 per cent of all the review videos in the sample. The majority of this technical equipment was related to filmmaking; gadgets reviewed were cameras and filming equipment such as lenses, handles, sliders, dollies, tripods and software plug-ins. These technical film

\begin{tabular}{|l|l|l|l|l|l|l|l|}
\hline Category & $\begin{array}{l}\text { N } \\
\text { videos }\end{array}$ & $\%$ & $\begin{array}{l}\text { N } \\
\text { producers }\end{array}$ & $\begin{array}{l}\text { \% } \\
\text { Av. N } \\
\text { likes } \\
\text { per } \\
\text { video }\end{array}$ & $\begin{array}{l}\text { Av. N } \\
\text { followers } \\
\text { per } \\
\text { producer }\end{array}$ & Examples \\
\hline Technical film equipment & 1,004 & 79 & 476 & 78 & 70 & 2.1 & $\begin{array}{l}\text { Cameras and filming } \\
\text { equipment }\end{array}$ \\
\hline Film & 98 & 8 & 48 & 8 & 68 & 2.0 & Films \\
\hline Clothes & 56 & 4 & 13 & 2 & 72 & 4.3 & $\begin{array}{l}\text { Underwear, } \\
\text { sportswear }\end{array}$ \\
\hline Games & 36 & 3 & 11 & 2 & 40 & 3.3 & Videogames \\
\hline Other consumer products & 19 & 1 & 16 & 3 & 20 & 1.0 & Cars, sports gear \\
\hline Events & 15 & 1 & 14 & 2 & 76 & 1.1 & Festivals, shows, fairs \\
\hline Food & 11 & 1 & 3 & 0 & 36 & 3.7 & Restaurants, pizza \\
\hline Music & 9 & 0 & 9 & 1 & 134 & 1.0 & Albums \\
\hline Other & 25 & 2 & 19 & 3 & 155 & 1.3 & Miscellaneous \\
\hline Total ${ }^{*}$ average & 1,273 & 100 & 609 & 100 & $* 533$ & $* 2.2$ & - \\
\hline
\end{tabular}

Table 1. The cultural areas reviewed on Vimeo. 
equipment reviews were thus tech or gadget reviews related to the overarching topic of the Vimeo community, film and filmmaking.

Film reviews included heterogeneous approaches to film content. A major producer, with 40 videos in the sample, was a user focused on reviewing niche cultural products, namely aesthetic products of gay culture such as gay films and television programmes, but even comic books and toys. In general, the films reviewed were not blockbusters but often works by other professionals of an "indie" nature, rather technically analysed in order to learn from them for an improved performance.

Game reviews featured a rather minor group of videos, which is perhaps not surprising as Vimeo has explicitly sought distance from gaming communities. In 2008-2014, gameplay videos were not allowed on Vimeo because they did not assume compliance with the quality requirements of creative expression. Gameplay videos referred to captures of video plays that could be "game walk-throughs, game strategy videos, depictions of player vs player battles, raids, fraps" and videos "that simply depict individuals playing a video game" (Whitman 2008). Even though this ban is now lifted, Vimeo is apparently still not the first alternative for gamers to publish commentaries on games. In comparison, among the 200 most subscribed review channels on YouTube, over 20 per cent were game review channels (Jaakkola 2018), and the world's best-known gamers, like PewDiePie and Markiplier, have established their brand on YouTube.

The rest of the video review types included quite a few items, showing a great diversity in approaches and styles and stemming from a limited number of producers following the review format. For example, food reviews were mostly published by two producers who call themselves "experts", who eat and discuss pizza and call their videos "review shows". Most of the few music reviews were connected to music festivals. Other consumer products included cars, bikes, skates, kiteboards, flysurfers and skimboards. The category "Other" presents a residual category featuring reviews of diverse objects that did not form groups and could not be put into any other category, such as books, filmmakers and book authors, and a roller coaster.

This said, the majority of user reviewers who have chosen Vimeo are clearly filmmakers and filming enthusiasts from the field of film and media production. Video reviewers on Vimeo make out a distinct group of content-producing consumers, or, to be more exact, prosumers (Toffler, 1980) or produsers (Bruns, 2008). Instead of establishing an ordinary consuming citizen's relationship to the objects of everyday or aesthetic consumption, the Vimeo reviewers occupy the role of professional customers in the area of consumption they represent (filmmaking). 
More specifically, the core of the reviewers is formed by film gadget reviewers $(\mathrm{N}=27)$ who are mostly professional (or semi-professional) filmmakers testing equipment in their "free time." Many of the film reviewers also add to this group of filmmakers or hands-on practitioners, focusing on the technical aspects of image quality or the creation of special effects in films. What these reviewers share in common is that they position themselves vis-à-vis the producers of cultural content rather than being part of film audiences, or they can at least be regarded as the DIY enthusiasts of the film or video scene. They are practitioners, and they are using their expertise and practical knowledge from the technical production of videos to test and evaluate new products. As a by-product of their primary expertise, they are producing knowledge to assist other media makers in their choices of camera equipment. This dimension of being in service for others is distinctively characteristic of the review videos. This anchors the Vimeo review videos powerfully in a tradition of films and audiovisual output that has been discussed in the framework of usefulness. Therefore, I will in the next section localise the review videos as a specific "utility genre", anchored in previous concepts of "useful media" and "useful culture", to understand their specific nature as a mixed manifestation of information, evaluation and education. Further, I will distinguish two ways of producing usefulness found in the sample and attempt to bridge them by using the concept of "useful creativity".

\section{Utility and Video Media}

In film studies, the concept of "useful media" has become to refer to a tradition of films that are functional, educational or non-fictional, and somewhat residual in film history-educational and training films, industrials, newsreels, travelogues, home videos, and so on. Acland and Wasson (2011:2) point out that these films are characterized less by their artistic and entertainment aims than by their "ability to transform unlikely spaces, convey ideas, convince individuals, and produce subjects in the service of public and private aims". They refer to useful cinema as "a body of films and technologies that perform tasks and serve as instruments in an ongoing struggle for aesthetic, social, and political capital" (Acland \& Wasson 2011: 3). In this respect, the videos are assigned a political or strategic function.

Acland and Wasson's concept of useful media is based on Tony Bennett's (1992) conceptualisation of culture's utility, or what he calls 'useful culture' as an institutional tool of governmental management of culture. Bennett connects usefulness to understanding the relations between culture and power in society. According to him, culture is always inscribed within governmental strategies or policies, and film entertainment is also part of these structures of governance. However, in a Foucaultian spirit he argues that working with government or policy 
issues does not have to imply neither the subjects' compliance nor acceptance. Accordingly, reviewing cannot be seen as separately from the platform governance that makes users act in a certain way. Vernacular reviewing is framed as much by the industry that produces and sells the equipment as by the professional producers need of knowing what tools are out there and how to choose between them. Besides, as can be seen in the sample, the latter clearly extends beyond an information need towards an endeavour of showing what can be done with these tools to support and participate in a lively film production scene.

Instead of the very macro-level concept of "useful media", I prefer the term "useful genre", which applies to all of the above mentioned examples of films. Accordingly, drawing on the aspect of usefulness, review, as it appears in the niche communities of Vimeo, can be characterised as a useful genre for managing the professional self or authorship via relationships to the technologies of production. Namely, while the review genre has a relatively stable tradition, as described above, one central difference between Vimeo reviews and traditional institutionalised reviewing is that while the trajectory and related conventions of the latter heavily lean upon producing judgements of works of art, the videos in the sample are based on producing judgements of consumer products or commodities. These products are not primarily evaluated on the basis of the aesthetic experiences or disinterested pleasure they happen to generate in the (re)viewer but the reviewer wants to prove how a product can be valuable in terms of use value: is it worth trying (and buying)? Aesthetic qualities such as design may play a role, but in general the shared aim among the Vimeo reviewers, particularly those reviewing film production gadgets, is pursuing the highest quality with the best possible cost-relationship. This comes close to the raison dêtre of consumer journalism, even if a very niched one, yet realised in the form of a customer review instead by consumer journalists following the strict set of ethical codes of journalism. While in a typical consumer review, the reviewer pronounces a judgement of a product based on his or her shopping experience, the useful reviews à la Vimeo are not as much about the consuming experience after the purchase of a product than about using a product in different ways and maintaining professionalism related to this product. The constant search for better technical quality and a high qualityprice ratio for purchases is thus strongly connected to the vernacular reviewers' filmmaking achievements and self-development. Similar sort of reviewing might be found online in, for example, in discussion forums, Facebook groups, blogs and vlogs related to playing and constructing instruments (e.g. guitars), in which consumption (of technical parts and utensils) and production (of instruments, music) are intertwined. 
In the sample, there is only one group of reviews where the opinion concerning the use value of the products remains rather an irrelevant question. This applies for clothes reviews that present male underwear $(\mathrm{N}=56)$ and are camouflaged reviews to present male soft-core pornography. While sexually explicit material and pornography on Vimeo are prohibited, artistic and non-sexual nudity are allowed in Vimeo's guidelines (Vimeo 2018c). Depictions of sexuality or nudity should "serve a clear creative, artistic, aesthetic, or narrative purpose" or be of a documentary nature (Vimeo, 2018a). It is likely that this undercover pornography - that can, even in the context of reviewing, be regarded as fake reviews-is invented for fending off these rules. "Reviewing" serves as a narrative excuse to present the male body, and the videos can be watched with both erotic and ironic intentions. This exploitation of the review genre to use it as covert porn demonstrates the flexibility of the functionality of the genre, but also resonates with the long history of non-preferred subcultures being spread to the audience as hidden messages. Nevertheless, it has to be admitted that these reviews are showing usefulness with regard to their producer (who is in order to present ideas in this specific form) and thus reveal the other dimension that is central to vernacular reviewing-usefulness to the author, will be discussed next.

\section{Two Dimensions of Usefulness}

Above it was identified that usefulness is set in relation to the expertise the video author represents and wants to make visible. Two dimensions of similar weight in the reviews can be distinguished: usefulness to others and usefulness to self. Usefulness to, or towards, others is something that can more clearly be found in classical reviews. Reviews are produced in an endeavour to help others and in order to be able to share one's own experiences. Usefulness to self is something that is a more characteristic trait of vernacular reviewing. In the classical review, the authorship is based on the integrity, aesthetic distinterestedness, and impartiality of the reviewing subject, i.e. distance towards the artworld (see e.g. Shrum 1996, Blank 2007). According to Bourdieu (1993), reviewers form a distinct field that establishes "a homology of tastes" to the audience field. Vernacular reviewers, in contrast, envisage themselves as experienced seniors in some kind of a tutor role; their pedagogical mission is to teach people with similar interests and goals to use tools better, but what is important is that they simultaneously conceive of themselves as part of that community. Shared interests can be seen in the somewhat childish enthusiasm the reviewers allow themselves, even on the most professionally-oriented side, such as in using the word "killer", and by using the pronoun "we" as a community marker. 
Indeed, a central intention in all the review videos is the mediation of an opinion or experience concerning a newly-launched product to a peer audience. This is in many cases a very exclusive and limited audience. For example, often, the professional vernacular reviews concerned the new version of the model and included a comparison to the previous version. These differences may appear rather tiny to many consumers, and they would hardly interest anyone other than "nerds" and enthusiasts-people who are regularly using the gadgets and software and need to know how to improve their performance through better tools. This impression is also supported by the language use, which includes the regular use of vocabulary that ordinary people have no idea about, such as "the M43 mount", "S-gamut", or "AVCHD codec", which were not typically explained. In addition, Vimeo provides many subcultures-from "film gadget nerds" to gay or queer cultures, or from aficionados of rather marginal sports to fans of a festivalwith a platform to cater to niche audiences, often in high proximity with these communities.

In the case of film equipment reviews, the "articulated opinion" judgement ('is something good or bad?') may take a variety of different forms-for example, testing or putting something into practice in comparison to something other, such as different versions of a gadget. Some of the videos hashtagged with \# review were short shots-typically called "test films"-marking the result of a filming and a simultaneous reviewing process, perhaps featuring some tests or alternative scenes at the end of the video. Or, for example, the video could include deconstructing and analysing well-known pieces of cinema. The professional vernacular reviews can thus be characterised as both connoisseurial or procedural reviews on consumer products, as defined by Blank (2007) in the institutionalised domain. Produced by an engaged group of users, they demonstrate, or at least aim to demonstrate, a high level of knowledge and experience upon which the assessments are based, showing parallels to the institutionalised forms of reviewing. Yet the overarching question is "is this useful or not?" rather than "is this good or bad?", putting the use value of the object to the foreground, instead of the aesthetic or symbolic value.

Usefulness to self manifests in two major ways: as creativity and self-development of the producer on one hand and as public positioning and an extension of self-PR on the other. Individual Vimeo videos that had gained over 1,000 likes were a slow-motion video test showing liquids and motions $(3,879$ likes), a comparison video on shooting in dark and at daylight (2,149 likes), a "review" of the career of the film director Emmanuel Lubezki, a tribute similar to a video essay (1,982 likes) and a technical review of the BlackMagic Cinema Camera (1,754 likes). They point to the fact that, particularly in audiovisual works, the poetics of a particular piece become an important feature; they are not only 
watched as reviews or tests of something, but also for their aesthetic and poetic accomplishment, as artworks in their own right. At the same time, these skilful pieces demonstrate the ability of their producers to make films of high technical and aesthetic quality and enforce their positioning as professionals or professional amateurs in the field of film production. In other words, the review videos are manifestations of production and consumption processes that are essential to a free-time activity, hobby, part-time occupation or even full-time profession of the video producer.

The reviewers on Vimeo are seemingly not primarily led by the logics of attention to aspire to the widest possible number of views in order to get their activities financed and/or to get commercial partnerships and, in that way, to make their content production more economically profitable. However, it would be naïve to presume that they only have altruistic goals. Quite obviously, reviewing provides filmmakers with a boost to their personal brand and establishes them as authorities in the field of video or film production, while at the same time making their own professional or amateur activity meaningful and more structured. Reviewing can thus also be allotted to the context of career development and personal brand building. This also adds the aspect of "venture labour" to the vernacular reviewing activities (Geff 2012); for the professional vernacular reviewers, creating a review profile is visibility work that Baym (2015: 20) calls "relational labour", part of "ongoing communicative practices and skills of building and maintaining interpersonal and group relationships central to maintaining many careers".

\section{Dependencies of Useful Creativity}

In both types of usefulness in Vimeo reviews, usefulness is characterised by negotiations between two, partially contradictory, positionings. First, in the usefulness to others, the reviewing activity juggles between negotiations between promotion of products and creating distance to the industry. Reviewers are part of the circulation of goods, adding to the symbolic value of products on the market by making intermediary interventions in the form of reviews and thus being positioned to the value chain originated from the industry. Indeed, some of the most sophisticated review videos appeared like commercials for the products, trying to show off, for example, a camera in perfect studio conditions. Simultaneously, Vimeo reviewers attempt to resist the "selling function" and create integrity by establishing an ethical code to testify of autonomy and professionalism.

A central dimension in creating a convincing professional image and communicating usefulness is the trustworthiness of the producers' output. In the traditional review, independence was guaranteed by the intermediary organisation 
that commissioned the reviewer and stood for his or her professional integrity and third-party position. To create trustworthiness, the vernacular reviewers produce a lot of metadiscourse around the review. In the sample, they dedicated space to explain the specific choices or occurrences that lead to certain decisions concerning the review that was published by the media for which they were working. One of the most frequent professional reviewers, Philip Bloom-who also declared in one of his videos that "without my ethics, my opinion is pointless" (Bloom 2013)-explained in an attached blog (Bloom 2014):

I am extremely choosy about which cameras I review. I have to be interested in them to put the huge amount of time and effort it takes to make them. If I have no interest in a camera, then I simply won't make a review. They are occasionally subsidized by a dealer, never the company who makes them due to my ethics (this one CVP are subsidizing) but even then they're $90 \%$ self-funded. I am not sure they could stomach the actual cost of all the time I put into making them!

However, the vernacular reviewers' critical authority is not a simple and unproblematic issue, and this still distinguishes them from institutionalised reviewers, for whom the intermediary organisation that commissions the review serves as a guarantor. Even if the vernacular reviewers act in good faith, a "good consumer bias" may occur, similar to the "good citizen" bias identified among survey respondents, who for the sake of social desirability or other causes tend to self-report about themselves more positively than what they, in reality, are. The social desirability bias may make the reviewers present their products in a more positive light, and the economic bound may result in reinforcing the popularity of certain brands in the community: Having made a decision to spend your money on something, which may be relatively pricey, as is the case for a good deal of camera equipment, you may not want your choice to appear as a complete failure.

Second, reviewing being part of the politics of creating the professional self, the usefulness to self is divided into the altruistic ambitions of helping others to learn and develop and the efforts of promoting self on the employment market. The first dimension is manifest in the practices of peer pedagogies of putting things into practice, the latter in the narrative of a ready-to-be-employed experienced and creative filmmaker. As peers-specialised amateurs-the reviewers see themselves as part of a community willing to share the newest home-made test results. Indeed, in the commentary field many users reinforced the pedagogical aspect; for example, to a test footage users could ask if they were any new findings regarding some specific technical features of the gadget reviewed, and the reviewer could provide the audience with more hands-on experience. The other side of helping 
others was the effort of self-branding-standing out as an expert, or to be seen as an expert, referring to professional traits, such as naming a client, mentioning the reviewer's name or using a logo of one's own.

Contentwise, the useful creativity on Vimeo is not homogeneous: it can be characterised as something that ranges from a serious enthusiasts' laboratory to an arena of shared impressions and co-consumption. Yet what is striking is that the review sphere is an all-male community: nearly all the producers of Vimeo reviews in the sample are males. The range of interests concerning products to be reviewed reflect activities typically favoured by males (technology, cars, extreme sports). The review genre, in this niche form, seems to resonate with the gender bias found on some other social media platforms such as Wikipedia (Reagle \& Rhue 2011). The male dominance of the reviewing sector thus does not make any exception to the gender gap found among filmmakers (Lauzen 2018a), or to the fact that issues in popular culture are more likely to be covered by male journalists (Jaakkola 2015), and film reviewers more often tend to be men (Lauzen 2018b).

\section{Conclusion}

The aim of this study was to describe and map the review videos published on the video-sharing platform Vimeo to increase our understanding of reviews and reviewing beyond the institutional framework and thus help in theorising further about reviewing in the digital era. While the creation of content in its produsage forms has been richly theorised on different platforms, the specific genre of reviewing is a phenomenon that has perhaps been dominated by the examination of its institutionalised forms, not having been able to make it to an object of inquiry in its own right.

The object of inquiry has in this case been audiovisual, and all the findings cannot be directly applied to other forms of reviews. In particular, the audiovisual medium offers the possibility to show things in action: to test how equipment works, to show results of work, or to compare pieces or versions of work. This is suited particularly well to consumer products, where the audience of the review potentially has the immediate need to know if a product is usable or not. It was thus found that the review videos in the male-dominated Vimeo review sphere were to a high degree related to assessing and testing out film equipment and quality, by "produser" filmmakers with insiders' production knowledge. However, there was also another group of reviewers approaching reviewing from a position in the prosumership paradigm-as enthusiastic consumers delivering their reactions, presenting new products among the first ones, or simply sharing their delight in new consumer products such as sports gear. 
As there seem to be different grades of specialization, or "professionalism" and "amateurism", even in the vernacular sphere of reviewing, ingrained with "produsage" and "prosumption", a more nuanced picture of vernacular forms of reviewing is needed to further resist the simplified binary opposition of "professional" and "amateur", which has to a great extent come to characterise the scholarly discussions on reviewing so far. Reviewing seems to be closely connected to a certain subject-discipline, or "scene", in which it is acted out in attachment to other scene-specific discourses and practices. "Cross-scene" analyses may miss out on the specific features of these subcultures, but holistic perspectives are important to add to our understanding of reviewing as a user-generated phenomenon. Furthermore, with regard to the male dominance among producers, the study suggests that gender issues remain an important factor to examine in the practice of reviewing.

Maarit Jaakkola, $\mathrm{PhD}$, is Associate Professor, Co-Director of the Centre for Nordic Media Research Nordicom at the University of Gothenburg, Sweden. Jaakkola also works as a Lecturer in Journalism at the Faculty of Information Technology and Communication Sciences at Tampere University, Finland. Jaakkola's research interests are localized at the intersection of theories of media, culture, and learning. She has recently studied user-generated cultural content, cultural journalism, and the signature pedagogy of journalism education. E-mail: maarit.jaakkola@gu.se

\section{Notes}

1 The script YoutubeStats was written by Pasi Luostarinen (BeTeK) and released at https://github.com/BeTeK/YoutubeStats (2018).

2 A list of such producers ( $\mathrm{N}=27)$ in alphabetical order: Safwan Ahmedmia, Matthew Allard, Johnnie Behiri, Cinema5D, Dave Dugdale, emmagination, GayComicGeek, Rod Guadajardo, Philip Bloom, Stefan Czech, Mark, Martin Foerster, Gizmodo, Tom Guilmette, John Hope, Philip Johnston, Gordon Laing, Nino Leitner, Erik Naso, OSWreview, Daniel Peters, Caleb Pike, Andrew Reid, Ron Risman, ShutUpShow, UNB Blog, Chris Weatherly. All these producers had eight or more videos in the sample included.

\section{References}

Acland, Charles R. \& Wasson, Haidee (eds.) (2011): Useful Cinema. Durham: Duke University Press.

Alexander, Victoria D. (2010): Sociology of the Arts: Exploring Fine and Popular Forms. Malden: Blackwell Publishing. 


\section{Culture Unbound}

Journal of Current Cultural Research

Baym, Nancy K. (2015): "Connect with Your Audience! The Relational Labor of Connection". The Communication Review, 18:1, 14-22.

Beaudouin, Valérie \& Pasquier, Dominique (2017): "Forms of contribution and contributors' profiles: An automated textual analysis of amateur on line film critics." New Media \& Society, 19:11, 1810-1828.

Bennett, Tony (1992). "Useful culture." Cultural Studies 6(3), 398-408.

Beuscart, Jean-Samuel \& Mellet, Kevin (2016): "Shaping consumers' online voices: Algorithmic apparatus or evaluation culture?" Robert Seyfert, \& Jonathan Roberge (eds): Algorithmic Cultures: Essays on Meaning, Performance, and New Technologies. London and New York: Routledge, 88-106.

Blank, Grant (2007): Critics, Ratings, and Society: The Sociology of Reviews. Lanham: Rowman \& Littlefield Publishers.

Bloom, Philip (2013): "Review of the Canon 1DC" Vimeo, January 26 2013. Retrieved from https://vimeo.com/58263312

Bloom, Philip (2014): "The no longer evolving review of the Sony A7S now with extreme low light video", Philip Bloom, July 3 2014. Retrieved from http:// philipbloom.net/blog/a $7 \mathrm{~s} /$

Bourdieu, Pierre (1993): The Field of Cultural Production: Essays on Art and Literature. Cambridge: Polity Press.

Bruns, Axel (2008): Blogs, Wikipedia, Second Life and Beyond. New York: Peter Lang.

Bruns, Axel (2016): "User-Generated Content," Klaus Bruhn Jensen, Robert T. Craig, Jefferson D. Pooley, \& Eric W. Rothenbuhler (eds): The International Encyclopedia of Communication Theory and Philosophy. Oxford: Wiley-Blackwell, 1-5.

Burgess, Jean E. (2006): "Hearing ordinary voices: Cultural studies, vernacular creativity and digital storytelling," Continuum: Journal of Media and Cultural Studies, 2, 201-214.

Carroll, Noël (2009): On Criticism: Thinking in Action. New York: Routledge.

Conti, Olivia (2013): "Disciplining the Vernacular: Fair Use, YouTube, and Remixer Agency," M/C Journal, 16:4. Retrieved from http://www.journal.media-culture. org.au/index.php/mcjournal/article/view/685.

Corner, John (2013): "Criticism': Notes on the Circulation of Cultural Judgement," JOMEC Journal, 3:4.

Domsch, Stefan (2009): "Critical Genres: Generic Changes of Literary Criticism in Computer-Mediated Communication," Janet Giltrow \& Dieter Stein (eds): Genres in the Internet. Amsterdam: John Benjamins Publishing Company, 221-238.

Frey, Mattias \& Sayad, Cecilia (eds) (2015): Film Criticism in the Digital Age. New Brunswick: Rutgers University Press.

Geff, Gina (2012): Venture Labor: Work and the Burden of Risk in Innovative Industries. Cambridge and London: The MIT Press.

Gibbs, Martin, Meese, James, Arnold, Michael, Nansen, Bjorn \& Carter, Marcus (2015): "\#Funeral and Instagram: Death, social media, and platform vernacular," Information, Communication \& Society, 18:3, 255-268.

Gillespie, Ryan (2012): "The art of criticism in the age of interactive technology: Critics, participatory culture, and the avant-garde," International Journal of Communication, 6:1, 56-75.

Goes, Paulo B., Lin, Mingfeng \& Yeung, Ching-man Au (2014): "“Popularity effect' in user-generated content: Evidence from online product reviews," Information Systems Research, 25:2, 222-238.

Gronow, Jukka \& Warde, Alan (2011): Ordinary Consumption. London and New York: Routledge.

Hohendahl, Peter Uwe (1982): Institution of Criticism. Ithaca: Cornell University Press.

Howard, Robert Glenn (2008): "The vernacular web of participatory media," Critical Studies in Media Communication, 25:5, 490-513. 


\section{Culture Unbound}

Journal of Current Cultural Research

Howard, Robert Glenn (2010): "The vernacular mode: Locating the non-institutional in the practice of citizenship," Daniel C. Brouwer \& Robert Asen (eds) Public Modalities: Rhetoric, Culture, Media, and the Shape of Public Life. Tuscaloosa: The University of Alabama Press, 240-262.

Ito, Mizuko (2010): "The rewards of non-commercial production: Distinctions and status in the anime music video scene," First Monday, 15:5.

Jaakkola, Maarit (2015): The Contested Autonomy of Arts and Journalism: Change and Continuity in the Dual Professionalism of Cultural Journalism. Tampere: Tampere University Press.

Jaakkola, Maarit (2018): "Vernacular reviews as a form of co-consumption: The user-generated review videos on YouTube." MedieKultur: Journal of Media and Communication Research, 34:65, 10-30.

Kammer, Aske (2015): "Post-industrial cultural criticism: The everyday amateur expert and the online cultural public sphere," Journalism Practice, 9:6, 872-889.

Keen, Andrew (2007): The Cult of the Amateur: How Blogs, MySpace, YouTube and the Rest of Today's User Generated Media are Killing our Culture and Economy. New York: Doubleday.

Kristensen, Nete Nørgaard \& From, Unni (2017): "From ivory tower to cross-media personas: The heterogeneous cultural critic in the media," Nete Nørgaard Kristensen \& Unni From (eds) Cultural Journalism and Cultural Critique in the Media. Abingdon: Routledge, 94-112.

Lauzen, Martha M. (2018a): The Celluloid Ceiling: Behind-the-Scenes Employment of Women on the Top 100, 250, and 500 Films of 2017. San Diego: Center for the Study of Women in Television and Film. Retrieved from https://womenintvfilm. sdsu.edu/wp-content/uploads/2018/01/2017 Celluloid Ceiling_Report.pdf

Lauzen, Martha M. (2018b): Thumbs Down 2018: Film Critics and Gender, and How it Matters. San Diego: Center for the Study of Women in Television and Film. Retrieved from https://womenintvfilm.sdsu.edu/wp-content/ uploads/2018/07/2018 Thumbs Down Report.pdf

McAuley, Julian \& Leskovec, Jure (2013): "From amateurs to connoisseurs: Modeling the evolution of user expertise through online reviews." In: $W W W$ ' 13 Proceedings of the 22nd international conference on World Wide Web. New York: Association for Computing Machinery, 897-908.

McWhirther, Andrew (2016): Film Criticism and Digital Cultures: Journalism, Social Media and the Democratization of Opinion. London: IB Tauris.

McWhirther, Andrew \& Lee, Kevin B. (2018): “Andrew McWhirther \& Kevin B. Lee in dialogue 'on videographic pedagogies in the era of mass social media." Screen, 24 March 2018.

Orlik, Peter B. (2016): Media Criticism in a Digital Age: Professional and Consumer Considerations. London: Taylor \& Francis.

Quora (2018): "How is Vimeo similar to and different from YouTube?" Retrieved from https://www.quora.com/How-is-Vimeo-similar-to-and-different-from-YouTube

Reagle, Joseph \& Rhue, Lauren (2011): "Gender bias in Wikipedia and Britannica," International Journal of Communication, 5:1, 1138-1158.

Rixon, Paul (2017): "The impact of new forms of digital communication on press-based TV critics and the emergence of new forms of critical debate," Journalism, 18:2, 226-240.

Shirky, Clay (2008): Here Comes Everybody: The Power of Organizing without Organizations. New York: Penguin Press.

Shrum, Wesley Monroe Jr. (1996): Fringe and Fortune: The Role of Critics in High and Popular Art. Princeton: Princeton University Press.

Steiner, Ann (2010): "Personal readings and public texts: Book blogs and online writing about literature," Culture Unbound, 2:2, 471-494.

Titchener, Campbell B. (1998): Reviewing the Arts. 3rd ed. New York: Lawrence Erlbaum. 
Toffler, Alvin (1980): The Third Wave. London: Collins.

Verboord, Marc (2010): "The legitimacy of book critics in the age of the Internet and omnivorousness: Expert critics, Internet critics and peer critics in Flanders and the Netherlands," European Sociological Review, 26:6, 623-637.

Verboord, Marc (2011): "Cultural products go online: Comparing the Internet and print media on distributions of gender, genre and commercial success," Communications: The European Journal of Communication Research, 36:1, 441-462.

Verboord, Marc (2012): "Exploring authority in the film blogosphere: Differences between male and female bloggers regarding blog content and structure", Interactions: Studies in Communication and Culture, 2:3, 243-259.

Verboord, Marc (2014): "The impact of peer-produced criticism on cultural evaluation. A multilevel analysis of discourse employment in online and offline film reviews," New Media \& Society, 16:6, 921-940.

Vimeo (2018a): "How does Vimeo determine the difference between pornography and artistic or non-sexual nudity?" Legal FAQs. Retrieved from https://help. vimeo.com/hc/en-us/articles/224978088-How-does-Vimeo-determine-the-difference-between-pornography-and-artistic-or-non-sexual-nudity-

Vimeo (2018b): "Tell me more about that commercial content exception," Legal FAQs. Retrieved from https://help.vimeo.com/hc/en-us/articles/115012753687Tell-me-more-about-that-commercial-content-exception-)

Vimeo (2018c): Vimeo Guidelines. Retrieved from https://vimeo.com/help/guidelines Whitman, Blake (2008): "New upload rules," The Vimeo Blog, July 212008. Retrieved from https://vimeo.com/blog/post/new-upload-rules

Zimmer, Michael (2010): "But the data is already public: On the ethics of research in Facebook." Ethics and Information Technology, 12:4, 313-325. 